\title{
Serum magnesium in association with parathyroid hormone levels in routine hemodialysis patients
}

\author{
Milad Fooladgar ${ }^{1}$, Afsaneh Malekpour ${ }^{2}$, Shahin Asgari-Savadjani ${ }^{3}$, Saeed Mardani ${ }^{*}$
}

\begin{abstract}
Introduction: The homeostasis of magnesium $(\mathrm{Mg})$ is perturbed in chronic kidney disease. It has been supposed that plasma $\mathrm{Mg}$ has a principal role to regulate the secretion of parathyroid hormone (PTH). Plasma Mg is capable of modulating secretion of PTH. Recent investigations showed that low serum Mg levels in patients with kidney disease have been linked to increased mortality. Objectives: The aim of this study was to determine the relationship between serum Mg and PTH levels in hemodialysis patients. Patients and Methods: This cross-sectional study was conducted on 56 hemodialysis patients in hemodialysis center of Hajar hospital of Shahrekord in 2015. Regular hemodialysis patients who had at least three months history of dialysis were enrolled to the study. The serum levels of Mg, calcium, phosphorus, intact PTH (iPTH), alkaline phosphatase, albumin and bicarbonate were measured. Results: In this study, $61.5 \%$ of the 52 patients were male. Mean \pm standard deviation (SD) of patients' age was $60.5 \pm 17.7$ years with median of 63 years old. The average duration of dialysis was $44 \pm 39.5$ months (median 36 months). Additionally the dialysis dose was $517 \pm 479$ weeks (median; 414 weeks). Mean \pm SD of serum iPTH and Mg were $360.1 \pm 238.2 \mathrm{pg} / \mathrm{mL}$ and $2.2 \pm 0.2 \mathrm{mg} / \mathrm{mL}$ respectively. In this study we found a significantly positive correlation of $\mathrm{iPTH}$ with serum $\mathrm{Mg}$ levels $(\mathrm{r}=0.28, P=0.04)$.

Conclusion: This study shows impact of $\mathrm{Mg}$ on parathormone secretion. Our findings require further investigations with larger and multicentric studies.

Please cite this paper as: Fooladgar M, Malekpour A, Asgari-Savadjani S, Mardani S. Serum magnesium in association with parathyroid hormone levels in routine hemodialysis patients. J Parathyr Dis. 2018;6(1):13-15. DOI: 10.15171/jpd.2018.05.

Copyright (๑) 2018 The Author(s); Published by Nickan Research Institute. This is an open-access article distributed under the terms of the Creative Commons Attribution License, which permits unrestricted use, distribution, and reproduction in any medium, provided the original work is properly cited.
\end{abstract}

\section{Introduction}

One of the most important disorders of chronic renal failure is chronic kidney disease-mineral bone disorder (1). Parathyroid hormone (PTH) is a principal parameter in the pathogenesis of bone disease in dialysis patients. The homeostasis of phosphorus, calcium, and magnesium $(\mathrm{Mg})$ is distorted in chronic renal failure $(2,3) . \mathrm{Mg}$ is largely excreted by kidney. The homeostasis of $\mathrm{Mg}$ is perturbed in chronic kidney disease. In fact, kidney has a fundamental role in the homeostasis $\mathrm{Mg}$. The regulation of $\mathrm{Mg}$ metabolism is influenced by filtration and reabsorption (4). Hyperphosphatemia, hypermagnesemia and hypocalcemia are detectable in advanced chronic kidney disease. Disturbances in Mg metabolism in chronic renal failure may partly contribute to the development of chronic kidney disease-mineral bone disorder $(5,6)$. It has been supposed that plasma $\mathrm{Mg}$ has a principal role to regulate the secretion of PTH. Plasma Mg is capable of modulating secretion of PTH. Recent investigations revealed low serum $\mathrm{Mg}$ levels in patients with kidney disease have been linked to increased mortality. It has been detected that that lower plasma $\mathrm{Mg}$ values are related to calcification of cardiac tissue and vessel walls which will increase mortality and morbidity in hemodialysis patients (5-9).

\section{Objectives}

The aim of this study was to assess the relationship of serum $\mathrm{Mg}$ with $\mathrm{PTH}$ in a group of hemodialysis patients.

\section{Patients and Methods \\ Study population}

The present cross-sectional study was conducted in the hemodialysis center of Hajar hospital of Shahrekord in 2015. Regular hemodialysis patients who had three months history of dialysis were included to the study. Exclusion criteria were any active or chronic infection and a history of malignancy. Around 52 eligible patients were included to the study.

Blood samples were collected to assess levels of calcium, $\mathrm{Mg}$, alkaline phosphatase, intact $\mathrm{PTH}$, albumin, and vitamin D using special standard kits. Plasma HCO3 was assessed by arterial blood gas. The serum calcium levels of blood was corrected with regard to the albumin levels. 
Implication for health policy/practice/research/ medical education

In a study on 52 hemodialysis patients, we found a significantly positive correlation of iPTH with serum magnesiumlevels.

Duration of dialysis and dialysis doses (calculated by sessions of dialysis per week $\times$ duration of dialysis; dialysis doses) was assessed too.

The efficiency of hemodialysis was calculated by assessing the urea reduction rate (URR) (10).

\section{Ethical issues}

The research followed the tenets of the Declaration of Helsinki. Written informed consent was obtained from all patients. This study was approved by Ethical Committee of Shahrekord University of Medical Sciences and extracted from M.D thesis.

\section{Statistical analysis}

For statistical analysis, descriptive data are expressed as mean \pm SD. We applied Spearman's correlation coefficient for correlations. All statistical analyses were performed using SPSS version 18 (SPSS Inc., Chicago, IL, USA). $P$ values less than 0.05 were considered as significant level and the data were reported as mean $\pm \mathrm{SD}$.

\section{Results}

In this study, $61.5 \%$ of 52 patients were male. Mean \pm SD of patients' age was $60.5 \pm 17.7$ years with median of 63 years old (minimum age; 13 years old, maximum age; 52 years old). The average duration of dialysis was $44 \pm 39.5$ months (median 36 months). Additionally the dialysis dose was $517 \pm 479$ weeks (median; 414 weeks). URR was $0.61 \pm 0.16 \%$. Mean \pm SD of serum $\mathrm{iPTH}$ and $\mathrm{Mg}$ were $360.1 \pm 238.2 \mathrm{pg} / \mathrm{mL}$ and $2.2 \pm 0.2 \mathrm{mg} / \mathrm{mL}$ respectively. The result of laboratory assessments are shown in Table 1. In this study we found a significantly positive correlation of iPTH with serum Mg levels ( $r=0.28, P=0.04$, Figure 1$)$.

\section{Discussion}

In this study we found a significant positive correlation of serum PTH with levels of plasma Mg. In a crosssectional study on 41 hemodialysis patients, Baradaran

Table 1. The result of laboratory assessments in patients undergoing hemodialysis

\begin{tabular}{lc}
\hline Variable & Average \pm SD \\
\hline Calcium $(\mathrm{mg} / \mathrm{dL})$ & $9.1 \pm 0.53$ \\
Albumin $(\mathrm{g} / \mathrm{dL})$ & $4.1 \pm 0.36$ \\
Bicarbonate $(\mathrm{mEq} / \mathrm{L})$ & $21.1 \pm 2.8$ \\
ALP $(\mathrm{IU} / \mathrm{L})$ & $266.2 \pm 120.5$ \\
Phosphorus $(\mathrm{mg} / \mathrm{dL})$ & $5.3 \pm 1.1$ \\
Intact PTH $(\mathrm{pg} / \mathrm{mL})$ & $360.1 \pm 238.2$ \\
Mg $(\mathrm{mg} / \mathrm{dL})$ & $2.2 \pm 0.2$ \\
Vitamin D $(\mathrm{ng} / \mathrm{ml})$ & $14.4 \pm 5.5$ \\
\hline
\end{tabular}

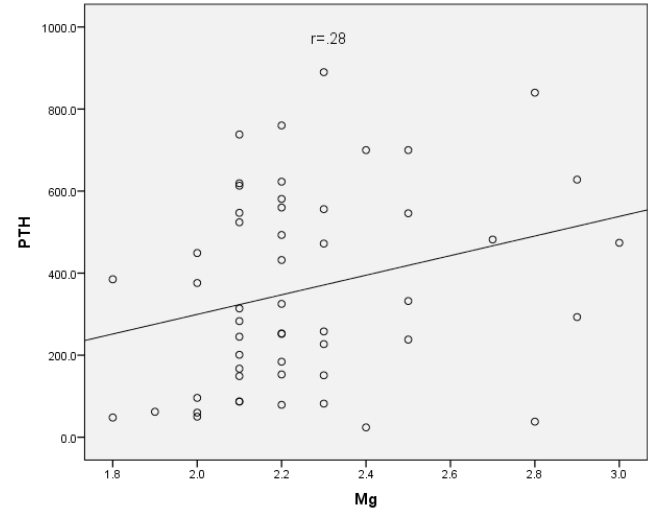

Figure 1. Relationship of serum Mg with levels of parathormone.

et al detected an inverse correlation, albeit insignificant, between serum $\mathrm{Mg}$ value and levels of iPTH $(r=-0.30$ $P=0.079$ ) (11). Likewise, in the study of Zeraati et al serum $\mathrm{Mg}$ levels was $1.00+0.14 \mathrm{mg} / \mathrm{dL}$. They also found a weak and inverse relationship between $\mathrm{Mg}$ serum level and iPTH, which was not statistically significant. They observed an inverse significant correlation of $\mathrm{Mg}$ and PTH levels in patients with serum PTH of above 300 pg/ $\mathrm{ml}$. However, in patients with serum PTH levels less than $300 \mathrm{pg} / \mathrm{mL}$, no correlation of serum $\mathrm{Mg}$ with PTH was detected (12). To find the association of serum $\mathrm{Mg}$ and intact parathormone levels in CKD patients just prior to beginning hemodialysis, Ohya et al conducted a study on 1231 patients in nine Japanese centers who had started hemodialysis for end-stage renal disease. They found serum Mg levels were significantly elevated in patients with low iPTH (13). Consistent with above-mentioned studies, Navarro et al also detected an inverse correlation of serum Mg with PTH levels. The study conducted on 110 hemodialysis individuals with mean age of $55 \pm 14$ years and the duration of dialysis was $35 \pm 28$ months (14). To find association of serum PTH and Mg levels in continuous ambulatory peritoneal dialysis subjects using low-Mg peritoneal dialysate, Cho et al detected that parathormone level was not associated with serum $\mathrm{Mg}$ level. They found patients whose serum parathormone was less than $300 \mathrm{pg} / \mathrm{mL}$, serum parathyroid levels were inversely associated with serum $\mathrm{Mg}$ level (15).

\section{Conclusion}

To conclude, hypermagnesemia reduces PTH secretion, which is detected as a risk factor for calcification of vessel walls, hypertrophy of left ventricle and increasing mortality in hemodialysis. While numerous investigations have detected that patients with higher serum $\mathrm{Mg}$ tend to have lower PTH levels, some of these studies may have methodological limitations (16).

\section{Limitations of the study}

Proportion of hemodialysis patients is relatively small. We suggest larger multicentric investigations on this aspect of hemodialysis individuals. 


\section{Acknowledgements}

This paper is extracted from M.D thesis of Milad Fooladgar (proposal\# 2012 and thesis \#1293) in Shahrekord University of Medical Sciences.

\section{Authors' contribution}

SM, SAS and MF conducted the researsh. AM conducted the statistical analysis. MF prepared the primary draft. SM revised and prepared the final manuscript. All authors read and signed the final paper.

\section{Conflicts of interest}

The authors declared no competing interests.

\section{Ethical considerations}

Ethical issues (including plagiarism, data fabrication, double publication) have been completely observed by the authors.

\section{Funding/Support}

This study was funded by Shahrekord University of Medical Sciences.

\section{References}

1. Moe SM, Drüeke T, Lameire N, Eknoyan G. Chronic kidney disease-mineral-bone disorder: a new paradigm. Adv Chronic Kidney Dis. 2007;14:3-12.

2. Ahmadi F, Mohebbi Z, Mahdavi-Mazdeh M, LessanPezeshki M. Relationship of circulating levels of 25(OH) vitamin $\mathrm{D}$ with parathyroid hormone in Iranian patients with chronic kidney disease not yet on dialysis; what is the best threshold for 25(OH) vitamin D. J Parathyr Dis. 2017;5:32-7.

3. Fukagawa M, Yokoyama Y, Koiwa F, Taniguchi M, Shoji T, James J et al. Clinical practice guideline for the management of chronic kidney disease-mineral and bone disorder. Therap Aph Dial. 2013;7:247-88.

4. Li W, Zhang S. Risk factors of parathyroid dysfunction in elderly patients with chronic kidney disease undergoing hemodialysis. Adv Clin Exp Med. 2015;24(6):1007-12. doi: $10.17219 /$ acem/23439.

5. Kenny MA, Casillas E, Ahmad S. Magnesium, calcium and PTH relationships in dialysis patients after magnesium repletion. Nephron. 1987;46:199-205.

6. Gonella M, Bonaguidi F, Buzzigoli G, Bartolini V, Mariani G. On the effect of magnesium on the PTH secretion in uremic patients on maintenance hemodialysis. Nephron. 1981;27:40-2.

7. Navarro JF, Mora C, Macia M, Garcia J. Serum magnesium concentration is an independent predictor of parathyroid hormone levels in peritoneal dialysis patients. Perit Dial Int. 1999;19:455-61.

8. Cho MS, Lee KS, Lee YK, Ma SK, Ko JH, Kim SW, et al. Relationship between the serum parathyroid hormone and magnesium levels in continuous ambulatory peritoneal dialysis CAPD patients using low-magnesium peritoneal dialysate. Korean J Intern Med. 2002;17:114-21.

9. El Tayeb AA, Abd El-Mottaleb NA, Abdel Aziz EA. Relationship between serum parathyroid hormone and trace elements (serum zinc and magnesium) in hemodialyzed chronic renal failure children. Biol Trace Elem Res. 2009;128:128-34. doi:10.1007/s12011-008-8265-x.

10. Boag JT. Basic truths in optimal hemodialysis. Dial Transplant. 1994;23:636.

11. Baradaran A, Nasri H. Correlation of serum magnesium with serum parathormone levels in patients on regular hemodialysis. Saudi J Kidney Dis Transpl. 2006;17:344-50.

12. Zeraati AA, Naghibi M, Aminian A, Sharifipour F, Hekmat R, Beladi Mousavi S. Correlation between serum magnesium and serum pth levels in patients with peritoneal dialysis. J Birjand Univ Med Sci. 2011;18:151-8.

13. Ohya M, Negi S, Sakaguchi T, Koiwa F, Ando R, Komatsu Y, et al. Significance of serum magnesium as an independent correlative factor on the parathyroid hormone level in uremic patients. J Clin Endocrinol Metab. 2014;99(10):38738. doi: 10.1210/jc.2013-4396.

14. Navarro JF, Mora C, Jiménez A, Torres A, Macía M, García J. Relationship between serum magnesium and parathyroid hormone levels in hemodialysis patients. Am J Kidney Dis. 1999;34:43-8.

15. Cho MS, Lee KS, Lee YK, Ma SK, Ko JH, Kim SW, et al. Relationship between the serum parathyroid hormone and magnesium levels in continuous ambulatory peritoneal dialysis CAPD patients using low-magnesium peritoneal dialysate. Korean J Intern Med. 2002;17:114-21.

16. Cunningham J, Rodríguez M, Messa P. Magnesium in chronic kidney disease stages 3 and 4 and in dialysis patients. Clin Kidney J. 2012;5:i39-i51. doi: 10.1093/ndtplus/sfr166. 